\title{
Social Phobia Presenting with Recurrent Transient Impaired Reality Testing: A Case Study
}

\author{
${ }^{1}$ Ravi M Sharma, ${ }^{2}$ Anurag Timothy, ${ }^{3} \mathrm{D}$ Bhattacharyya
}

\begin{abstract}
Aim: Approach to a case with social phobia that presented with recurrent transient delusions of reference and persecution and responded with anti-anxiety medication without the need for antipsychotics.
\end{abstract}

Background: Social phobia presents with symptoms of fear of scrutiny by other people in public, usually leading to avoidance of social situations. It is uncommon to have associated referential or persecutory ideations in it. In the present case study, we bought about a case with a social phobia that presented with recurrent transient delusions of reference and persecution, which responded to anti-anxiety measures alone.

Discussion: Paranoid symptoms in the background of severe anxiety in social phobia may be explained by three models (a) Inability to challenge suspected criticism; (b) Presence of stressor leading to transient psychotic breakdown; (c) Understanding the disorder itself as a primary thought abnormality rather than an effective disturbance. In our case, despite paranoia, the patient responded satisfactorily to anti-anxiety measures alone, without the need of antipsychotics.

Conclusion: Acute onset paranoia arising in a patient with a history of social phobia should get the benefit of being treated with anti-anxiety measures before starting antipsychotics, as they may respond satisfactorily to anti-anxiety measures alone and exposing patients to long-term side effects of antipsychotics may be unwarranted.

Keywords: Acute and transient psychotic disorder, Delusion, Social anxiety disorder, Social phobia.

How to cite this article: Sharma RM, Timothy A, Bhattacharyya D. Social Phobia Presenting with Recurrent Transient Impaired Reality Testing: A Case Study. Journal of Medical Academics (JOMA) 2018;1(1):65-67.

\section{Source of support: Nil}

Conflict of interest: None

\section{INTRODUCTION}

Social phobia is an anxiety spectrum disorder, which revolves around symptoms of fear of scrutiny by other

\footnotetext{
${ }^{1}$ Psychiatry Resident, ${ }^{2}$ Assistant Professor, ${ }^{3}$ Professor

${ }^{1-3}$ Department of Psychiatry, Army College of Medical Sciences, Delhi, India
}

Corresponding Author: Ravi M Sharma, Psychiatry Resident, Department of Psychiatry, Army College of Medical Sciences, Delhi, India, Mobile: +918010992801, e-mail: drravi14nov@ gmail.com people in a small group, usually leading to avoidance of social situations. ${ }^{1}$ Anxiety may be related to public speaking, encountering known people or social situations. Selfreferential ideas although common in social phobia, it is uncommon to have paranoid symptoms with impaired reality testing into it. The present case brings about the presence of psychotic symptoms in patients suffering from social phobia, which responded satisfactorily to anti-anxiety measures alone, without the need for antipsychotics.

\section{CASE PRESENTATION}

A 43-year-old male, government employee, office clerk by trade, self reported to primary care physician for complains of nervousness on exposure to social situations since adolescence and intermittent belief that his office colleagues refer him in their conversation and were conspiring against him and could harm him, for which he was referred for psychiatric evaluation.

Although anxious since childhood, the onset of distressing symptoms was since 19 years of age in 1994, after failing in class $12^{\text {th }}$. He started considering himself inferior to others. Although eager to make friends, he would have a lack of confidence in initiating talk with friends in a group, leading to avoidance of his friend circle. He would fear to talk nonsense or something out of context and getting embarrassed. Gradually over next one year, he started feeling that people stare at him, and judge him, whenever he would be in a social gathering. While traveling in buses, he would take the back seat, to avoid people noticing him. He realized that his thinking was unreasonable, but despite that, he could not participate in social gatherings and avoided them. At the age of 22 years, he joined government service as a clerk. While working in office also, his feeling of inferiority to other colleagues persisted, despite no reason to feel so. Whenever he would have a change of workplace environment, during the initial few weeks, he would remain apprehensive of coping up with newly assigned work. Whenever he would be called by superiors for explaining about the documents, he would have difficulty in expressing himself despite having complete knowledge about the matter in hand. On one occasion while purchasing a dress for his spouse from a garment shop, he had to wait for 15 to 20 minutes for alteration in dress, during which he became 
extremely anxious and started believing that the lady shopkeeper was deliberately delaying the work and was humiliating him. He became so much distressed with the belief that he left the place, leaving his spouse and children there. In April 2011 he got posted to a new place and was facing difficulty in coping with tasks given to him in the new environment. He asked for leave to fetch his family which could not be granted, because of exigencies of service, following which he contemplated that he was not being sent on leave deliberately by his superior officer. His anxiety increased to the extent that he believed that he was not safe in a new environment and would be punished by his superior officer for his incapability to handle assigned duties. He remained fearful and could not sleep over the next two nights and absented without leave, to save himself. At home, over the next few days, he realized that his fear was irrational and returned to his workplace with his family.

He continued to remain apprehensive of demanding social situations such as an encounter with superiors in any matter and would fear criticism and disapproval from them. He would experience significant distress associated and face difficulty in pursuing his duties often. But despite that, there was never a significant decline in his performance. In Feb 2017 he again asked for leave as he perceived increased scrutiny by his superiors, and when denied by his immediate senior, he believed that he was not being sent on leave deliberately and was being deliberately overburdened. He remained irritable and faced difficulty in handling day to day routine tasks for next 2 to 3 days during which he also believed that any general comments made by his colleagues in a group were directed towards him. He developed firm belief that his colleagues were referring him in their conversation and planning to harm him and hence he confronted them for the same, though all his colleagues denied such discussion/plan. He also had episodes of intense anxiety characterized by restlessness, palpitation, tremors, dryness of mouth, tightness of chest and difficulty in breathing which would last for few minutes and resolve on its own. After 2 to 3 days he realized the falsity of his believes started working in the company of same people. Three days before his psychiatric referral he was told by his superior officer to show and explain about one important document file of which patient was in-charge. He felt distressed as how he would be able to explain about the file and to mitigate his distress he consumed 180-240 $\mathrm{ml}$ of alcohol at night, following which his anxiety got aggravated further, and he continued to have fear of being framed by his colleagues, immediate senior and superior officer collectively and over the next
2 days, he was restless, not sitting at one place, unable to sleep properly, that lead to his self-reporting to primary care physician and subsequent psychiatric referral.

There was no history suggestive of agoraphobia, depressive episode or any first-rank symptom of schizophrenia.

There was no history of seeking any psychological help. No family history of any psychiatric illness.

He was shy in childhood and would not come out of the room when some relative or stranger would come home. He would have difficulty in asking questions in the class and interacting with peers in groups, leading to avoidance of group activities and facing academic difficulties.

Premorbidly he described himself to be shy but eager to make friends and had a good relation with them. His predominant mood was anxious. He had religious and health conscious attitude. He read books and watched TV in leisure time.

General physical examination revealed tachycardia, fine digital tremors, and cold palms. Systemic examination was within normal limits. Relevant investigations including hemogram, liver/kidney/thyroid function tests, electrocardiography, ultrasound abdomen, and NCCT brain were within normal limits. Mental state exam revealed kempt, a cooperative individual who sat on the edge of the chair, was fidgety and appeared in the hyper-aroused state with eyes wide open, beads of sweat on forehead, dry lips (would take out tongue frequently to moisten them). Mood conveyed as Bechain rehta hai (remains restless) with anxious affect. He had apprehensions of being in social situations especially under supervision and fear of criticism by others. He had reduced self-confidence and self-esteem. Cognitive distortions in the form of arbitrary inference and catastrophic thinking were present. He had transient delusions of reference and persecution which arose off and on in social settings/ stressful situations. He had intermittent impairment of judgment and insight.

An individual was diagnosed and managed as a case of social phobia (ICD 10 F 40.1). Differential diagnosis of acute and transient psychotic disorder (the predominantly delusional type with relapsing nature) was also kept in mind. He was managed with Tablet Escitalopram (up to $20 \mathrm{mg} /$ day), relaxation training, cognitive behavior therapy, and family therapy. He was psycho-educated about the nature and course of illness. He responded slowly but satisfactorily to treatment and was given 4 weeks convalescence (sick leave). He gradually gained insight into his symptoms, and after sick leave, he rejoined duties. Over next one year follow up he main- 
tained improvement in his anxiety with no recurrence of paranoid symptoms.

\section{DISCUSSION}

Presence of paranoid symptoms in social phobia has been reported in multiple case studies. There could be three explanations for the delusional manifestations. ${ }^{2}$ Firstly a patient who is anxious in a social setting is unable to challenge others for suspected criticism and gradually develops paranoia. A second possibility would be that the presence of stressor/substance use may destabilize a known case of social phobia and produce an acute and transient psychotic disorder (predominantly delusional type) like the picture. Thirdly there could be a possibility that social phobia is a manifestation of a primary thought abnormality rather than affective disturbance, which can lead to intense concern about others' opinions. There is the possibility of psychotic symptoms in social phobia patients related to concomitant drug use or during the withdrawal phase. ${ }^{3}$ The association of social phobia with paranoid symptoms is consistent with the finding by Michail and Bischwood ${ }^{4}$ that social anxiety and persecutory thinking develop concurrently in the early phase of psychosis and follow a similar course. A D2 receptor hypo-activity observed in social phobia patients ${ }^{5,6}$ may be responsible for the lower efficacy of antipsychotics in patients suffering from social phobia and anti-anxiety drugs such as SSRI, gabapentin or pregabalin are the mainstay of treatment which effectively treats not only anxiety but also short lasting psychotic symptoms arising in the setting of social phobia.

\section{CONCLUSION}

In the present case study, we brought about the presence of psychotic symptoms in a patient of social phobia which responded to treatment with anti-anxiety doses of SSRI. Concluding, acute onset psychotic symptoms arising in a patient with a history of social phobia should get the benefit of being treated with anti-anxiety measures before starting antipsychotics, as they may respond satisfactorily to anti-anxiety measures alone.

\section{ACKNOWLEDGMENT}

Authors would like to thank all the faculty members and colleagues from the Department of Psychiatry, for their guidance in the evaluation and management of the case and their support.

\section{REFERENCES}

1. World Health Organisation, The ICD-10 Classification of Mental and behavioural Disorders: Clinical Descriptions and Diagnostic Guidelines. Geneva, WHO, 1992.

2. André B Veras, Júlia S do-Nascimento, Regis L Rodrigues, Ana Carolina A Guimarães, Antonio E Nardi. Psychotic symptoms in social anxiety disorder patient: report of three cases. Int Arch Med. 2011;4:12.

3. Karila L, Petit A, Phan O, Reynaud M. Cocaine induced psychotic disorders: a review. Rev Med Liege. 2010;65(11): 623-627

4. Michail M, Birchwood M. Social anxiety disorder in firstepisode psychosis: incidence, phenomenology and relationship with paranoia. Br J Psychiatry. 2009;195(3):234-241.

5. Furmark T. Neurobiological Aspects of Social Anxiety Disorder. Isr J Psychiatry Relat Sci. 2009;46(1):5-12.

6. Mathew SJ, Coplan JD, Gorman JM. Neurobiological Mechanisms of Social Anxiety Disorder. Am J Psychiatry. 2001;158(10):1558-1567. 